\title{
Open surgery in endovascular aneurysm repair era: simplified classification in two risk groups owing to factors affecting mortality in 137 ruptured abdominal aortic aneurysms (RAAAs)
}

\author{
Stefano Bonardelli • Edoardo Cervi • Roberto Maffeis • Franco Nodari • \\ Maurizio De Lucia • Cristina Guadrini - Fabio Viotti · Nazario Portolani • \\ Stefano Maria Giulini
}

Received: 13 September 2010/Accepted: 31 January 2011/Published online: 19 February 2011

(C) The Author(s) 2011. This article is published with open access at Springerlink.com

\begin{abstract}
Our objective is to identify in 137 true RAAAs operated consecutively in open surgery: (1) diagnostic therapeutic aspects capable of influencing results, (2) risk classes with different prognosis, (3) any situations where the prognosis is so negative that surgery is not recommended. The relationship of 16 anamnestic, clinical and technical parameters prospectively collected with 30-day mortality was retrospectively evaluated by uni- and multivariate analyses. Thirty-day mortality was $37 \%$. The univariate analysis identified as mortality predictors $\mathrm{Hb} \leq 8 \mathrm{~g} / \mathrm{dl}$ and circulatory shock at hospitalisation, but following the multivariate analysis only circulatory shock was a certainly significant risk-factor. The cumulative effect on mortality of the two parameters identified at univariate analysis translates into a statistically significant
\end{abstract}

\footnotetext{
S. Bonardelli

Department of Medical and Surgical Sciences,

Unit and Chair of Vascular Surgery, Università degli Studi,

A.O. Spedali Civili Brescia, Brescia, Italy

E. Cervi - R. Maffeis - F. Nodari - M. De Lucia - C. Guadrini ·

F. Viotti $\cdot$ S. M. Giulini

Department of Medical and Surgical Sciences,

Unit and Chair of Clinical Surgery, Università degli Studi,

A.O. Spedali Civili Brescia, Brescia, Italy

N. Portolani

Department of Medical and Surgical Sciences,

Unit and Chair of Emergency Surgery, Università degli Studi,

A.O. Spedali Civili Brescia, Brescia, Italy

C. Guadrini ( $\square)$

Dipartimento di Scienze Mediche e Chirurgiche,

Segreteria Chirurgia Vascolare, Clinica Chirurgica,

A.O. Spedali Civili, Policlinico Satellite Piazzale Spedali Civili 1,

25124 Brescia, Italy

e-mail: cristina.guadrini@gmail.com
}

difference in mortality between two groups of patients: A (no or just one risk-factor) and B (two risk-factors). To reinstate euvolemia, rather than adequate haemoglobin values, improves the chances of success. A simple prognostic index into two risk classes is feasible, but abstention from surgery is not justified in any type of patient.

Keywords Aortic aneurysm - Abdominal - Ruptured · Open surgery · Prognosis

\section{Introduction}

The most recent reviews of the literature [1, 2] show that the high mortality that still characterises ruptured abdominal aortic aneurysms (RAAAs) today can be the result of numerous types of variables, including logistic ones (such as the frequent transfers of the patient from the place where he was first hospitalised to reference Centres), to anagraphic-anamnestic and clinical variables of the patient themselves and, finally, to those relating to diagnostictherapeutic technique and timing. With reference to the variables mentioned above, we have compared the mortality found in 137 RAAAs treated consecutively in open surgery with numerous related factors, to identify: (1) risk classes with different prognosis, (2) aspects relating to the diagnostic-therapeutic management of the patient influencing results; (3) any situations where the prognosis is so serious that surgery is not recommended.

\section{Materials and methods}

Data from 137 consecutive patients undergoing open surgery repair with a confirmed diagnosis of ruptured 
abdominal aortic aneurysm (RAAA) were prospectively collected and retrospectively evaluated. Rupture was defined as extravasation of blood outside the aortic wall (extra-aortic haematoma) confirmed by computed tomography (CT) and/or during laparotomy. Four patients died at the time they were admitted to Emergency \& Admittance Unit (E\&A) and another 39 patients, operated urgently due to fissuring and/or acute symptomatology, but without true rupture, were not considered.

The relationship of 16 parameters (Table 1) with 30-day mortality was analysed by both univariate and multivariate analyses performed, respectively, through a Chi-square test and Logistic Regression model according to SPSS statistical software (version 13; SPSS, Chicago, IL, USA). Finally, the cumulative effect of the risk factors found to be significant in the univariate analysis was considered, dividing the patients into three classes according to the number (ranging from 0 to 2 ) of risk-factors present at the same (Table 2). The last statistical comparison among mortalities of the three classes then allow further simplification into just two groups of patients: A (no or just one risk-factor) and B (two risk-factors).

\section{Study group}

Of the 137 patients, 119 were men (87\%) with an average age of 72 (range 45-95, IQR 66-77) and 18 women (13\%) with an average age of 80 (range 71-95, IQR 76-82); 58 patients were $\geq 75$ years old, and among these, 36 were over eighty (Table 3 ).

In 63 cases $(46 \%)$, the patient arrived under our observation after initial hospitalisation in another Hospital. On
Table 2 Classes relative to the number of risk factors for mortality identified at univariate analysis and present at the same time in each patient

\begin{tabular}{llc}
\hline No. of risk-factors & No. of patients (\%) & Mortality (\%) \\
\hline 0 & $33(24)$ & $5(15)$ \\
1 & $63(46)$ & $21(33)$ \\
2 & $35(26)$ & $22(63)$ \\
\hline
\end{tabular}

entering our hospital, 83 patients (61\%) had localised pain in the abdomen, back or both and 74 patients (54\%) had circulatory shock (defined as systolic blood pressure $\leq 80 \mathrm{mmHg}$ ).

Following a haemochemical test carried out immediately after admission to hospital, haemoglobin values $(\mathrm{Hb}) \leq 8 \mathrm{~g} / \mathrm{dl}$ were found in 12 patients $(8.7 \%)$.

From the anamnestic and laboratory data, the various comorbidities indicated in Table 4 emerged.

69 patients $(50 \%)$ were operated within $6 \mathrm{~h}$ of the start of symptomatology, while the remaining 68 were operated after $6 \mathrm{~h}$. While 23 patients (17\%) underwent surgical treatment on the basis of the clinical assessment, supported by a scan carried out in E\&A, an Angio-CT was performed on 86 patients. In these cases, it was possible to measure the maximum diameter of the lesion, with an average of $7.38 \pm 1.94 \mathrm{~cm}$ (range $3.10-13.56 \mathrm{~cm}$ ): in particular, in $16 / 86$ patients $(18.8 \%)$ the maximum diameter was $\leq 5.5 \mathrm{~cm}$.

The extension of the aneurysm was suprarenal in 9 patients (6\%), juxtarenal in $16(12 \%)$ and infrarenal in 112 (82\%). In the 112 infrarenal cases, clamping was performed above the renal arteries in 19 patients (17\%),
Table 1 Statistical analysis of 16 parameters considered correlated to 30-day mortality

Circolatory shock, systolic blood pressure $<80 \mathrm{mmHg}$ at hospitalization (before the procedure). Timing, time from the beginning of symptoms to the surgical operation

COPD preoperative chronic obstructive pulmonary disease [37], $C A D$ preoperative coronary artery disease [38], $C R F$ chronic renal failure (serum creatinine $>1.8 \mathrm{mg} / \mathrm{dl}$ ) (anamnestic data), $P A O D$ peripheral arterial occlusive disease for pre-operative Winsor index $<0.80$ (anamnestic data), $\mathrm{Hb}$ haemoglobin value, $E \& A$ emergency and admittance unit

\begin{tabular}{llll}
\hline Parameter & $\begin{array}{l}\text { Univaried } \\
\text { analysis }(p)\end{array}$ & $\begin{array}{l}\text { Multivaried } \\
\text { analysis }(p)\end{array}$ & Odds ratio \\
\hline Age & $\mathrm{ns}$ & - & 2.1 \\
$\mathrm{Sex}$ & $\mathrm{ns}$ & - & 1.2 \\
$\mathrm{COPD}$ & $\mathrm{ns}$ & - & 0.9 \\
$\mathrm{CAD}$ & $\mathrm{ns}$ & - & 1.2 \\
$\mathrm{CRF}$ & $\mathrm{ns}$ & - & 2.0 \\
Hypertension & $\mathrm{ns}$ & - & 0.8 \\
PAOD & $\mathrm{ns}$ & - & 1.1 \\
Diabetes & $\mathrm{ns}$ & - & 1.0 \\
Pain & $\mathrm{ns}$ & - & 0.5 \\
Hb $\leq$ g/dl in E\&A & $<0.025$ & $\mathrm{~ns}$ & 5.2 \\
Circolatory shock & $<0.005$ & $<0.005$ & 3.0 \\
Timing & $\mathrm{ns}$ & - & 1.8 \\
Diameter AAA & $\mathrm{ns}$ & - & 1.6 \\
Location AAA & $\mathrm{ns}$ & - & 1.7 \\
Clamping location & $\mathrm{ns}$ & - & 1.5 \\
Replacement type & $\mathrm{ns}$ & - & 1.7 \\
\hline
\end{tabular}


Table 3 Age and gender of 137 patients correlated to 30-day mortality

\begin{tabular}{llccccc}
\hline Age (years) & No. of patients $(\%)$ & Males & Females & Mortality (\%) & Mortality, M vs. F (\%) \\
\hline$<60$ & $10(7.3)$ & 10 & 0 & $2(20)$ & 20 vs. 0 & - \\
$60-75$ & $68(49.6)$ & 66 & 2 & $22(32.4)$ & 32 vs. 50 & ns \\
$75-80$ & $23(16.8)$ & 18 & 5 & $10(43.5)$ & 44 vs. 40 & ns \\
$\geq 80$ & $36(26)$ & 25 & 11 & $17(47.2)$ & 56 vs. 27 & ns \\
Total & 137 & 119 & 18 & $51(37.2)$ & 38 vs. 33 & ns \\
\hline
\end{tabular}

Table 4 Mortality and preoperative comorbidities

\begin{tabular}{lll}
\hline Pre-operative comorbidity & No. of patients (\%) & Mortality (\%) \\
\hline COPD & $46(33.6)$ & $16(34.8)$ \\
CAD & $56(40.9)$ & $22(39.2)$ \\
CRF & $44(32.1)$ & $21(47.7)$ \\
Hypertension & $67(48.9)$ & $23(34.3)$ \\
PAOD & $25(18.2)$ & $10(40)$ \\
Diabetes & $16(11.7)$ & $6(37.5)$ \\
\hline
\end{tabular}

$C O P D$ preoperative chronic obstructive pulmonary disease [37], $C A D$ preoperative coronary artery disease [38], $C R F$ chronic renal failure (serum creatinine $>1.8 \mathrm{mg} / \mathrm{dl}$ ) (anamnestic data), $P A O D$ peripheral arterial occlusive disease for pre-operative Winsor index $<0.80$ (anamnestic data)

infrarenal in the remaining $83 \%$. In 62 cases, an aortobi-iliac replacement was carried out (45\%), in 60 an aorto-aortic replacement $(44 \%)$, in 7 an aorto-bifemoral replacement $(5 \%)$ and in 5 an aorto-iliac and a femoral controlateral replacement ( $4 \%$ ); finally, in 3 cases ( 2 due to rupture of the duodenum and 1 for extreme fragility of the aortic wall) an axillo-bifemoral by-pass was performed (2\%). The corresponding blood transfusion was performed with an average number of five units of concentrated erythrocytes (range 0-13) per patient, as well as the interoperation auto-blood transfusion.

\section{Results}

Thirty-day mortality was 51/137 RAAAs (37\%): 1 of the $51(2 \%)$ died during induction, $5(10 \%)$ during surgery, 15 (29\%) during the first day after surgery, $3(6 \%)$ during the first week and 27 within 30 days (53\%). Postoperative complications, causes of death were: first day, rupture of the thoracic aorta, on the second day, 28 multi-organ failures (MOF) and 22 major adverse cardiovascular events. No patient died from graft-related reasons, but one patient who underwent aorto-aortic replacement died as a result of acute myocardial infarction on the fifth day after he underwent a femoro-femoral by-pass cross-over, followed by reinstatement of a normal distal perfusion, made owing to the thrombosis of the left iliac axis during the first day after surgery for RAAAs.

With regard to mortality, the $\mathrm{Hb}$ level and circulatory shock at hospitalisation was statistically significant in the univariate analysis among the 16 parameters. Similarly, circulatory shock at hospitalisation was a significant prognostic factor, for a mortality of $49 \%$ in 74 patients with SAP $\leq 80 \mathrm{mmHg}$, compared with a mortality of $23 \%$ observed in 63 patients with $\mathrm{SAP}>80 \mathrm{mmHg}(p<0.005)$.

Therefore, in total, the univariate analysis identified as mortality predictors $\mathrm{Hb} \leq 8 \mathrm{~g} / \mathrm{dl}$ and circulatory shock at hospitalisation, but following the multivariate analysis only circulatory shock was a certainly significant risk-factor. The cumulative effect on mortality of the two parameters identified at univariate analysis translates into a statistically significant difference in mortality between group A (26/96 patients without or with only one risk-factor, 27\%) and group B $(25 / 41$ patients with two risk-factors, 61\%) $(p<0.001)$.

\section{Discussion}

While for endovascular aneurysm repair (EVAR) in the case of RAAAs assessments regarding not only the results but also the same possibility of extensive implementation [3-8], are still underway, the experience in open surgery is very extensive, and even over-consolidated results are also subjected to a very high-operatory mortality (Table 5 [2, 9-30]).

In the last 20 years, there has been a drop in mortality of about $3.5 \%$ for every decade; this apparently modest result, probably due in particular to the routine use of interoperatory recovery auto-haemotransfusion and to the improvement in the measures adopted to prevent and treat MOF [24], could be reassessed considering the greater number of patients, who, compared with the past, manage to reach the hospital and the operating theatre alive, often very elderly and with many co-morbidities. However, what was recently calculated by Bown et al. [25], still remains true: during the 60 s operatory mortality from RAAAs was $55 \%$, in the $80 \mathrm{~s}, 48 \%$, but it is still currently over $40 \%$ (Table 5). As highlighted in the extensive review of literature published in January 2008 by Tambyraja [1], we must continue analysing significant prognostic factors for such 
Table 5 Review of the literature since 2000: mortality of RAAAs in open surgery

\begin{tabular}{llll}
\hline Author & Year & Patients & Mortality (\%) \\
\hline Heller [9] & 2000 & $6,7751^{\mathrm{a}}$ & $30,962(46)$ \\
Merlo [10] & 2001 & 123 & $55(45)$ \\
Years [11] & 2001 & 413 & $153(37)$ \\
Alonso-Perez [12] & 2001 & $144^{\mathrm{a}}$ & $(47)$ \\
Dimick [13] & 2002 & $813^{\mathrm{a}}$ & $382(47 \%)$ \\
Gutierrez-Morlote [14] & 2002 & 99 & $48(49)$ \\
Hans [15] & 2003 & 101 & $48(48)$ \\
Piper [16] & 2003 & 147 & $51(35)$ \\
Markovic [17] & 2004 & 229 & $123(54)$ \\
Calderwood [18] & 2004 & 137 & $77(56)$ \\
Dueck [19] & 2004 & $2,280^{\mathrm{a}}$ & $921(40)$ \\
Korhonen [20] & 2004 & $836^{\mathrm{a}}$ & $395(47)$ \\
Davidovic [21] & 2005 & 406 & $196(48)$ \\
Acosta [22] & 2006 & 141 & $104(74)$ \\
Laukontaus [23] & 2007 & 319 & $121(38)$ \\
Cho [2] & 2008 & 170 & $65(38)$ \\
Our experience & 2008 & 137 & $51(37)$ \\
\hline
\end{tabular}

${ }^{\text {a }}$ Multicentre registers

mortality, above all in order to assess if it is possible to improve the prognosis influencing the same, through the prompt, intensive adoption of adequate measures of a logistical type and by planning and implementing diagnostic-therapeutic strategies.

\section{Non-modifiable risk-factors}

The figures found in the literature regarding the nonmodifiable risk-factors, as advanced age and gender, are conflicting ([4, 7, 12, 20, 28, 32]). Our patients had an average age of 73 , and $42 \%$ were $\geq 75$ years old (Table 3 ). This limit did not appear to be significant for the increase in mortality at the univariate analysis (47 vs. $30 \%$ in younger patients), even though the Odds Ratio shows a 2.1 times higher risk in older patients. In our experience, we find a 53\% survival rate both in patients of 75 years of age and over considered globally and in only patients over eighty (also the only two operated patients older than 80 years survived). The figure of higher mortality in the female sex reported by several authors [28] is not confirmed by our experience (Table 1). It is interesting to note that the number of female patients out of the total number of RAAAs increases steadily with the increase in age, but we did not find that the female sex is a negative prognostic factor: mortality among women patients (33\%) is even apparently lower than that of men (38\%), a difference which, in any case, even stratifying patients according to increasing age, never reaches statistical significance.
Again, among factors that cannot be modified (anamnestic pathologies), all co-morbidities analysed (Table 4) do not appear to be crucial in relation to operatory mortality. The previous chronic renal failure (CRF) that various authors indicate as significant [11] does not reach significant levels in our opinion, therefore giving the Odds Ratio calculated for this parameter as 2: $48 \%$ mortality in patients with CRF versus $32 \%$ in patients with a normal renal function (ns).

\section{Modifiable risk-factors}

Going on to consider factors that may suggest a clinicaldiagnostic-therapeutic approach able to positively modify the prognosis, we must point out that we analysed in detail the progress of the patient only from the time he reached our hospital, since we did not have sufficient data to assess, in particular, the influence of the fact that $46 \%$ of our patients had initially been hospitalised in other Hospitals, and whether the transfer had been a positive or negative factor.

Anemisation with $\mathrm{Hb}$ values $\leq 8 \mathrm{~g} / \mathrm{dl}$ on arrival at $\mathrm{E} \& \mathrm{~A}$ is a significant parameter for mortality at univariate analysis $(p<0.025$, OR 5.2). A second factor, i.e., circulatory shock, is the only factor to also confirm itself as significant at multivariate analysis $(p<0.005$, OR 3.0), as if achieving the correct pre-operatory reinstatement of volemy as soon as possible can offer even better chances of success for the surgical operation than the achievement of optimal $\mathrm{Hb}$ values.

Other factors such as the morphological characteristics of RAAAs (pararenal rather than infrarenal extension) and technical, operatory details [2, 11, 12, 19], (type of aortic clamping, performed by us on the hiatus only in $17 \%$ of infrarenal aneurysms [in every case $<10^{\prime}$ ], with the advantage of avoiding a further ischemic insult to the splanchnic area) were not significant for the patient's survival, confirming that a specific consolidated experience is not a secondary parameter for the result of the operation [2, 9, 13, 23, 33]. Finally, only in specific reference centres, a correct assessment may be made to see if the technical option currently composed of the EVAR may be implemented, and above all if it can cause an improvement in results, even for RAAAs, as various indications recently published seem to suggest [3-7].

\section{Prognostic factors}

For the purpose of identifying prognostic indexes that also include the various risk-factors for RAAAs, various score systems have been used such as the POSSUM, the 
APACHE II, the Glasgow Aneurysm Score and the Hardman index, designed and validated for other acute surgical syndromes, but with results that are not univocal, and in any case difficult to use except for analysis of a retrospective type [29, 31, 34, 35]. In order to dispose of a prognostic index that is simple and rapid to calculate, already prior to operating, but obviously also to assess on the basis of objective data the long-term variations in the efficiency and efficacy of our work, also in relation to any adjustments in the diagnostic-therapeutic approach, modifying that already attempted by other authors [1, 31, 36], we decided to divide the patients under observation for RAAAs into two risk groups only that are easy to identify and which, on the basis of the data reported herein, appear to be completely different on the prognostic level: the first with a better prognosis includes patients who have no factor or only one of the significant risk factors $(27 \%$ mortality in our experience); the second, with a worse prognosis, includes patients with at least two risk-factors (63\% mortality, $p<0.001$ ). The considered risk factors are those that emerged from our experience: it is possible that different centres from ours identify other, different ones, given that every factor can have an absolute value, i.e., be the expression of aspects of variable significance or specific deficiencies.

Finally, these results allow confirmation that, since also in the group with the worse prognosis the survival rate is not insignificant (equal to 39\%), in these cases, it cannot be considered correct to abstain from a surgical treatment which not only saves the patient from certain death but also returns him to a life which in terms of quality and length is almost comparable to that of the general population.

Conflict of interest The authors declare that they have no conflict of interest.

Open Access This article is distributed under the terms of the Creative Commons Attribution Noncommercial License which permits any noncommercial use, distribution, and reproduction in any medium, provided the original author(s) and source are credited.

\section{References}

1. Tambyraja AL (2008) Prediction of outcome after abdominal aortic aneurysm rupture. J Vasc Surg 47:222-230

2. Cho JS, Kim JY, Rhee RY, Gupta NY, Marone LK, Dillavou ED, Makaroun MS (2008) Contemporary results of open repair of ruptured abdominal aortoiliac aneurysms: effect of surgeon volume on mortality. J Vasc Surg 48:10-18

3. Dillavou ED, Muluk SC, Makaroun MS (2006) Improving aneurysm-realted outcomes: nationwide benefits of endovascular repair. J Vasc Surg 43:224-229

4. Harkin DW, Dillon M, Blair PH, Ellis PK, Kee F (2007) Endovascular ruptured abdominal aortic aneurysms repair (EVRAR): a systematic review. Eur J Vasc Endovasc Surg 34:673-681
5. Acosta S, Lindblad B, Zdanowski Z (2007) Predictors for outcome after open and endovascular repair of ruptured abdominal aortic aneurysms. Eur J Vasc Endovasc Surg 33:277-284

6. Coppi G, Silingardi R, Gennai S, Saitta G, Ciardullo AV (2006) A single-centre experience in open and endovascular treatment of hemodynamically unstable and stable patients with ruptured abdominal aortic aneurysms. J Vasc Surg 44:1140-1147

7. Hinchliffe RJ, Bruijstens L, MacSweeney ST, Braithwaite BD (2006) A randomised trial of endovascular and open surgery for ruptured abdominal aortic aneurysm-results of a pilot study and lessons learned for future studies. Eur J Vasc Endovasc Surg 32:506-513 (discussion 514-5)

8. Hinchliffe RJ, Braithwaite BD (2007) Ruptured abdominal aortic aneurysm: endovascular repair does not confer any long-term survival advantage over open repair. Vascular 15:191-196

9. Heller JA, Weinberg A, Arons R, Krishnasastry KV, Lyon RT, Deitch JS, Schulick AH, Bush HL Jr, Kent KC (2000) Two decades of abdominal aortic aneurysm repair: have we made any progress? J Vasc Surg 32:1091-1100

10. Merlo M, Carignano G, Bitossi G, Leotta L, Mussano L, Levi S, Bau G, Narcisi P, Russo L (2001) Personal experience of the treatment of ruptured aortic aneurysms. The prognostic evaluation of some parameters. Minerva Cardioangiol 49:179-187

11. Years N, Gloviczki P, Cherry KJ (2001) Ruptured abdominal aortic aneurysm: the excessive mortality rate of conventional repair. J Vasc Surg 34:41-46

12. Alonso-Pérez M, Segura RJ, Sanchez J, Sicard G et al (2001) Factors increasing the mortality rate for patients with ruptured abdominal aortic aneurysm. Ann Vasc Surg 15:601-607

13. Dimick JB, Stanley JC, Axelrod DA, Kazmers A, Henke PK, Jacobs LA et al (2002) Variation in death rate after abdominal aortic aneurysmectomy in the United States: impact of hospital volume, gender and age. Ann Surg 235:579-585

14. Gutiérrez-Morlote J, Llorca J, Ibáñez de Elejalde E, Lobato A, San José JM (2002) Predictors of mortality in patients undergoing surgery for ruptured aortic aneurysm. Vasa 31:265-268

15. Hans SS, Huang RR (2003) Results of 101 ruptured abdominal aortic aneurysm repairs from a single surgical practice. Arch Surg 138:898-901

16. Piper G, Patel NA, Chandela S, Benckart DH, Young JC, Collela JJ, Healy DA (2003) Short-term predictors and long-term outcome after ruptured abdominal aortic aneurysm repair. Am Surg 69:703-709 (discussion 709-10)

17. Marković M, Davidović L, Maksimović Z, Kostić D, Cinara I, Cvetković S, Sindjelic R, Seferović PM, Ristić AD (2004) Ruptured abdominal aortic aneurysm. Predictors of survival in 229 consecutive surgical patients. Herz 29:123-129

18. Calderwood R, Halka T, Haji-Michael P, Welch M (2004) Ruptured abdominal aortic aneurysm. Is it possible to predict outcome? Int Angiol 23:47-53

19. Dueck AD (2004) Long-term survival and temporal trends in patient and surgeon factors after elective and ruptured abdominal aortic aneurysm surgery. J Vasc Surg 39:126-127

20. Korhonen SJ, Ylönen K, Biancari F, Heikkinen M, Salenius JP, Lepäntalo M (2004) Finnvasc Study Group Glasgow Aneurysm Score as a predictor of immediate outcome after surgery for ruptured abdominal aortic aneurysm. Br J Surg 91:1449-1452

21. Davidovic L, Markovic M, Kostic D, Cinara I, Markovic D, Maksimovic Z et al (2005) Ruptured abdominal aortic aneurysms: factors influencing early survival. Ann Vasc Surg 19:29-34

22. Acosta S (2006) Increasing incidence of ruptured abdominal aortic aneurysm: a population-based study. J Vasc Surg 44:237243

23. Laukontaus SJ (2007) Decrease of mortality of ruptured abdominal aortic aneurysm after centralization and in-hospital 
quality improvement of vascular service. Ann Vasc Surg 21:580 585

24. Maziak DE, Lindsay TF, Marshall JC (1998) The impact of MOF on mortality following rupture abdominal aortic aneurysm repair. Ann Vasc Surg 12:93-100

25. Bown MJ, Sutton AJ, Bell PR, Sayers RD (2002) A meta-analysis of 50 years of ruptured abdominal aortic aneurysm repair. $\mathrm{Br} \mathrm{J}$ Surg 89:714-730

26. Brewster DC, Cronenwett JL, Hallet JW Jr, Johnston KW, Krupsky WC, Matsumura JS, Joint Council of the American Association for Vascular Surgery and Society for Vascular Surgery (2003) Guidelines for the treatment of abdominal aortic aneurysms. Report of a subcommittee of the Joint Council of the American Association for Vascular Surgery and Society for Vascular Surgery. J Vasc Surg 37:1106-1117

27. Bernstein EF, Chan EL (1984) Abdominal aortic aneurysm in high risk patients: outcome of selective management based on size and expansion rate. Ann Surg 200:255-263

28. Alric P, Ryckwaert F, Picot MC et al (2003) Ruptured aneurysm of the infrarenal abdominal aorta: impact of age and postoperative complications on mortality. Ann Vasc Surg 17:277-283

29. Tambyraja AL, Fraser SCA, Murie JA, Chalmers RTA (2005) Validity of Glasgow Aneurysm Score and the Hardman index in predicting outcome after ruptured abdominal aortic aneurysm repair. Br J Surg 92:570-573

30. Tromp Meesters RC, Van Der Graft T, Vos A, Eikelboom BC (1994) Ruptured aortic aneurysm: early postoperative prediction of mortality using an organ system failure score. Br J Surg 81:512-516

31. Hardman DTA, Fisher CM, Patel ML, Neale M, Chambers J, Lane R, Appleberg M (1996) Ruptured abdominal aortic aneurysms: who should be offered surgery? J Vasc Surg 23:123-129

32. Akkersdijk G, Van Der Graf T (1994) Mortality rates associated with operative treatment of infrarenal abdominal aortic aneurysm in The Netherlands. Br J Surg 81:706-709

33. Bonardelli S, Parrinello G, De Lucia M, Nodari F, Maffeis R, Cervi E, Viotti F, Piardi T, Portolani N, Giulini SM (2007) Risk factors for immediate results and long-term survival following elective open surgery for AAA. Statistical analysis of 1111 consecutively treated patients. Ann Ital Chir 78(4):265-276

34. Neary WD, Croe P, Foy C, Prytherc D, Heather BP, Earnshaw JJ (2003) Comparison of POSSUM scoring and the Hardman Index in selection of patients for repair of ruptured abdominal aortic aneurysm. Br J Surg 90:421-425

35. Lazarides MK, Arvantis DP, Drista H, Staramos DN, Dayantas JN (1997) POSSUM and APACHE II scores do not predict the outcome of ruptured infrarenal aortic aneurysms. Ann Vasc Surg $11: 155-158$

36. Tambyraja AL, Amanda JL, Murie JA, Chalmers RTA (2008) Prognostic scoring in ruptured abdominal aortic aneurysm: A prospective evaluation. J Vasc Surg 47:282-286

37. Bateman ED, Feldman C, O'Brien J, Plit M, Joubert JR, COPD Guideline Working Group of the South African Thoracic Society (2004) Guideline for the management of chronic obstructive pulmonary disease (COPD): 2004 revision. S Afr Med 94:559-575

38. Krupski WC (2002) Update on perioperative evaluation and management for cardiac disease in vascular surgery patients. J Vasc Surg 36:1292-1308 